\title{
Restrictive cardiomyopathy
}

\author{
E.G.J. Olsen
}

National Heart Hospital, London WIM 8BA, UK

Under this heading are included endomyocardial fibrosis (Davies, 1948), believed to be confined to the tropical and sub-tropical regions of the world, and Löffler's endocarditis parietalis fibroplastica (Löffler, 1936), thought to be predominantly confined to the temperate zones. In the latter condition associated eosinophilia has been observed.

Macroscopically, endomyocardial fibrosis is characterized by immense thickening of the endocardium which in the normal left ventricle does not exceed 20 microns. Left, right or both ventricles may be affected and several patterns of distribution of this extremely thick endocardium, which can measure several millimetres, have been described (Shaper et al., 1968). In left ventricular involvement the posterior mitral valve apparatus is frequently involved together with the inflow tract, the apex and part of the outflow tract. In right ventricular involvement the apex and the region of the tricuspid valve are the principal sites of abnormal endocardial thickening and as the disease progresses the apex is obliterated and drawn towards the tricuspid valve (Olsen, 1983). Fibrous streaks or septa extend into the myocardium, occasionally reaching the epicardial regions. Histological examination shows diagnostic features. Beneath a layer of thrombus or fibrin lining the affected ventricular cavity a layer of collagen tissue is found, beneath which the socalled granulation tissue layer is identified. In this zone vascular channels are embedded in loosely arranged connective tissue as well as varying degrees of inflammatory cells including occasionally eosinophils. It is from this deepest layer that the fibrous septae extend into the underlying myocardium (Olsen, 1980).

Hearts from patients with Löffler's endocarditis parietalis fibroplastica show identical changes both at macroscopical and microscopical examination (Brockington \& Olsen, 1973).

The suggestion that both conditions might be the same disease was confirmed in a retrospective study in which some 90 patients previously described in the literature by numerous authors were reappraised (Brockington \& Olsen, 1973). They all had eosinophilia of varying severity either due to associated

\footnotetext{
Correspondence: E.G.J. Olsen, M.D., F.R.C.Path., F.A.C.C.
}

conditions such as polyarteritis nodosa, parasites, tumours or Hodgkin's disease in $25 \%$ of patients or in another $25 \%$ due to an ascribed diagnosis of eosinophilic leukaemia. In about half of the patients no cause for the eosinophilia could be established. Pathological material was available for study in 62 patients. The changes could be grouped into three major stages, each depending on the length of history. The necrotic phase occurred after an average length of history of 5 weeks and was characterized by an intense myocarditis rich in eosinophils. The intra-myocardial vessels showed an arteritis. After a history on average of 10 months the thrombotic phase could be identified showing often severe superimposition of thrombus over an already slightly thickened endocardium. The inflammatory process had largely receded and the lumina of intra-myocardial vessels were not infrequently occluded by thrombotic material. After an average of two and a half years the fibrotic stage was reached in which the changes already detailed above were observed. In this phase the small vessels showed nonspecific changes only consisting of varying degrees of intimal thickening by fibro-elastic tissue. Sixteen cases belonged to this stage and these were then compared with patients with endomyocardial fibrosis from the tropical and sub-tropical regions. No morphological differences could be established. It was therefore concluded that irrespective of the geographical origin endomyocardial fibrosis and Löffler's endocarditis parietalis fibroplastica belonged to the same disease process which begins with the presence of eosinophils in the myocardium.

Acceptance of the unitarian theory has been slow (Oakley \& Olsen, 1977); arguments against included the accompanying eosinophilia in the temperate zone, which common though it is in the tropics, had not been stressed as occurring in conjunction with endomyocardial fibrosis. Scrutiny of the literature has, however, shown that several reports testify to this association. Another argument against the unitarian approach stressed the absence of arteritis in the heart (and other organs) in tropical cases. It has been shown that arteritis is present in the early phase (the necrotic stage) only, and when the fibrotic stage is reached, non-specific intimal thickening is all that can be found. As most reports from the tropics describe the final stage of the disease process it is not surprising that 
arteritis is absent. Indeed, eosinophil counts are often normal in the late phase of the disease process. Though some clinical differences such as age, sex and incidence of thromboembolism exist (Davies et al., 1983), there is no doubt that 'both' conditions are the same and the term 'endomyocardial disease' is now applied.

Further extensive work has shown that the eosinophils are morphologically abnormal in that they show degranulation. It has been repeatedly shown that if $15 \%$ of circulating eosinophils are abnormal (i.e.

\section{References}

BROCKINGTON, I.F. \& OLSEN, E.G.J. (1973). Löffler's endocarditis and Davies' endomyocardial fibrosis. American Heart Journal, 85, 308.

DAVIES, J.N.P. (1948). Endocardial fibrosis in Africans. East African Medical Journal, 25, 10.

DAVIES, J., SPRY, C.J.F., VIJAYARAGHAVAN, G. \& DE SOUZA, J.A. (1983). A comparison of the clinical and cardiological features of endomyocardial disease in temperate and tropical regions. Postgraduate Medical Journal, $59,179$.

DAVIES, J., SPRY, C.J.F., SAPSFORD, R., OLSEN, E.G.J., DU PEREZ, G., OAKLEY, C.M. \& GOODWIN, J.F. (1983a). Cardiovascular features of 11 patients with eosinophilic endomyocardial diseases. Quarterly Journal of Medicine, 52, 23.

LÖFFLER, W. (1936). Endocarditis parietalis fibroplastica $\left.>1 \times 10^{9} / 1\right)$ endomyocardial disease is associated (Olsen \& Spry, 1979). Degranulated eosinophils have also been found in cases from the tropics (personal observation).

In 84 patients suspected of suffering from endomyocardial disease in all its stages, in over half these patients the majority of whom were in the early phases, the diagnosis had been confirmed in endomyocardial tissue obtained by bioptome. Early recognition and early treatment is now possible (Davies et al., 1983a).

mit Bluteosinophilie. Ein eigenartiges Krankheitsbild. Schweizerische Medizinische Wochenschrift, 66, 817.

OAKLEY, C.M. \& OLSEN, E.G.J. (1977). Eosinophilia and heart disease. British Heart Journal, 39, 233.

OLSEN, E.G.J. \& SPRY, C.J.F. (1979). In Progress in Cardiology, vol. 8, Yu, P.N. \& Goodwin, J.F. (eds). p. 281. Lea \& Febiger: Philadelphia.

OLSEN, E.G.J. (1980). In Pathology of the Heart, 2nd ed. p. 317. The MacMillan Press: London.

OLSEN, E.G.J. (1983). Pathological aspects of endomyocardial fibrosis. Postgraduate Medical Journal, 59, 135.

SHAPER, A.G., HUTT, M.S.R. \& COLES, R.M. (1968). Necropsy studies of endomyocardial fibrosis and rheumatic heart disease in Uganda. British Heart Journal, 30, 391. 